\title{
Brugada Syndrome was Uncovered with a Sodium Channel Blocker
}

\author{
Sodyum Kanal Blokeri ile Ortaya Çıkarılan Brugada Sendromu
}

\author{
Şerafettin Demir ${ }^{1}$, Mücahit Tüfenk ${ }^{2}$, Vedat Aslan ${ }^{3}$, Mehmet Kanadaşı', Zeynep Karakaya ${ }^{5}$ \\ 'Department of Cardiology, Adana State Hospital, Adana, Turkey \\ 2Department of Cardiology, Faculty of Medicine, Çukurova University, Adana, Turkey \\ ${ }^{3}$ Department of Cardiology, Şanlıurfa Balıklıgöl State Hospital, Şanlıurfa, Turkey \\ ${ }^{4}$ Department of Cardiology, Faculty of Medicine, Çukurova University, Adana, Turkey \\ ${ }^{5}$ Department of Emergency, Adana State Hospital, Adana, Turkey
}

\section{ABSTRACT}

Introduction: The Brugada syndrome is characterized by an STsegment elevation in the right precordial electrocardiography (ECG) leads and a high incidence of sudden death in patients with structurally normal hearts. Clinically, atypical chest pain, palpitations, syncope, supraventricular tachycardia, ventricular tachycardia, ventricular fibrillation and sudden death may occur.

Case Report: A 39 year old male patient was admitted with presyncope and palpitation symptoms to our clinic. A family history of sudden death presyncope and ECG findings brought the Brugada syndrome as a differential diagnosis to mind. To confirm the diagnosis, a provacation test with ajmanil was done. Serial performed ECGs have been evaluated and a Type 1 ECG sample which confirms the Brugada Syndrome has been observed in the patient.

Conclusion: Our goal is to help make the diagnosis of Brugada syndrome cases, a method comprising the use of the sodium channel blockers, and discuss case studies to introduce the method to provide ease of diagnosis.

Keywords: Brugada syndrome, sudden cardiac death, ajmaline Received: 18.04.2012 Accepted: 22.10.2012

\section{ÖZET}

Giriş: Brugada sendromu yapısal olarak normal kalpte sağ prekordiyal elektrokardiyografi (EKG) leadlerde ST segment elevasyonu ve artmış ani kardiyak ölüm riski ile karakterizedir. Klinik olarak atipik göğüs ağrısı, çarpıntı, senkop, supraventriküler taşikardi,ventriküler taşikardi, ventriküler fibrilasyon, ani ölüm şeklinde karşılaşılabilir.

Olgu Sunumu: Otuz dokuz yaşında erkek hasta çarpıntı, presenkop şikayeti ile kliniğimize başvurdu. Presenkop, ailede ani ölüm öyküsü ve EKG bulguları bir arada değerlendirilen hastada ön tanı olarak brugada sendromu düşünüldü. Tanıyı doğrulamak için hastaya ajmanil verilerek provakasyon testi uygulandı. Seri çekilen EKG'lerini değerlendirildi ve hastada Brugada sendromu tanısını doğrulayan Tip 1 EKG örneği gözlendi.

Sonuç: Amacımı Brugada sendromu düşünülen vakalarda tanı koymaya yardımcı bir yöntem olan sodyum kanal blokerlerinin kullanımını, vaka üzerinden tartışmak ve tanı kolaylığı sağlayacak yöntemi tanıtmaktır.

Anahtar Kelimeler: Brugada sendromu, ani kardiyak ölüm, ajmaline

Geliş Tarihi: 18.04.2012 Kabul Tarihi: 22.10.2012

\section{Giriş}

Brugada sendromu, yapısal olarak normal kalplerde sağ dal bloku ve sağ prekordiyal derivasyonlarda ST segment elevasyonu, senkop ve ani kardiyak ölümle karakterize bir sendromdur (1). Bütün ani ölümlerin yaklaşık olarak \%4-12'sini oluşturmaktadır. Semptomlar ve ani kardiyak ölüm, polimorfik ventriküler taşikardi ve ventriküler fibrilasyonla ilişkilidir (2). Bu sendromda elektrokardiyografi (EKG) bulguları geçici olarak normale dönebilmekte veya minimal değişiklik gösterebilmektedir (3). Brugada sendromu olduğundan şüphelenilen hastalarda, Na+ kanal blokaj etkisi olan farmakolojik ajanlarla (ajmalin, flekainid, prokainamid) tipik EKG örneği ortaya çıkarılabilir (4). Bu olgu sunumunda EKG'sinde tip 2 ve tip 3 EKG örneklerinin bir arada bulunduğu, ajmalin testi sonrası Tip 1 EKG örneğinin elde edilerek tanısı kesinleşen bir vaka sunuldu. 


\section{Olgu Sunumu}

Otuz dokuz yaşında erkek hasta çarpıntı, presenkop şikayeti ile kliniğimize başvurdu. Hastanın bu şikayetleri yaklaşık 6 yı önce başlamış ve son bir yılda yaklaşık 6-7 kez tekrarlamıştı. Hasta bu şikayetlerle birkaç kez acil servise başvurmuş, supraventriküler taşikardi düşünülerek beta bloker tedavisi başlanmıştı. Ayrıca hastanın aile öyküsünden, bir kuzenini 38 yaşında ani ölüm sonucu kaybettiği öğrenildi. Fizik muayenesinde kan basıncı 130/75 mmHg, nabzı 82/dk ve ritmikti. Diğer sistem muayeneleri doğaldı. Hastanın hemogram, kan biyokimyası ve göğüs radyografisi normal idi. Daha önce yapılan transtorasik ekokardiyografisi ve Holter EKG'si normal olarak değerlendirilmiş idi. Hastamızın elektrokardiyografisinde V1 derivasyonunda körfez tipi ve V2 derivasyonunda eğer tipi, 2 mm'den az ST segment elevasyonu olan tip2 ve tip 3 EKG örneklerinin birlikte olduğu EKG bulgusu mevcuttu (Resim 1). Presenkop, ailede ani ölüm öyküsü ve EKG bulguları bir arada değerlendirilen hastada ön tanı olarak brugada sendromu düşünüldü. Tanıyı doğrulamak için hastaya 5 dakikada $1 \mathrm{mg} / \mathrm{kg}$ dozunda bir sodyum kanal blokeri olan ajmanil verilerek provakasyon testi uygulandı. Seri çekilen EKG'lerini değerlendirildi ve hastada Brugada sendromu tanısını doğrulayan Tip 1 EKG örneği gözlendi (Resim 2). Hastadan çalışmaya dahil edildiği kabul ettiğine dair imzalı onam formu alınmıştır.

\section{Tartışma}

Illk olarak 1992 yılında Brugada kardeşler tarafından sendrom otozomal dominant geçiş gösteren bir hastalıktır. Genetik analizi yapılan bazı olgularda miyokartda bulunan sodyum kanalının alfa subünitesinin düzenlenmesinde sorumlu tutulan SCN5A geninde defekt saptanmıştır (5). Görülme sıklığı batı ülkelerinde 5/1000 civarında iken uzakdoğu toplumlarında 20/1000'e kadar çıkmaktadır. Erkeklerde, bayanlara göre 8 kat daha fazla rastlanmaktadır. Tipik olarak erişkin yaşta ortaya çıkan sendromun EKG bulguları geçici olarak kaybolduğundan, genel popülasyondaki sıklığını saptamak zorlaşmaktadır. Ortalama ani ölüm yaşı $41 \pm 15$ 'tir. Tanımlanmış en küçük hasta 2 günlük, en yaşlı hasta ise 84 yaşındadır $(5,6)$. Bizim hastamız 39 yaşındaydı ve aile öyküsünden 38 yaşındaki kuzenini ani ölümle kaybetmişti.

Brugada sendromunda başta iskemik kalp hastalığı olmak üzere, organik kalp hastalıklarından sağ ventrikül displazisinin ayırıcı tanısı yapılması gerekmektedir (3). Bizim hastamıza yapılan koroner anjiyografi ve transtorasik ekokardiyografi normaldi. Brugada sendromunun kliniğinden polimorfikventriküler taşikardi ve ventriküler fibrilasyon gelişmesi sorumlu tutulmaktadır. Hastaların yaklaşık \%20'sinde supraventriküler aritmiler görülebileceği bildirilmiştir (7). Hastamıza da önceden supraventriküler taşikardi tanısı konulup beta bloker tedavisi verilmişti.

Brugada sendromunda EKG'de V1-3 derivasyonlarında RBBB örneği ve beraberinde çadır tipi 2 mm'den fazla ST yükselmesi tipiktir. Bu EKG örneğine tip 1 adı verilmektedir. Tip 2'de RBBB örneği ve bununla beraber yine 2 mm'yi gecen ancak çadır tipi değil eyer tipi ST yüksekliği saptanmaktadır. Eğer mevcut ST yükselmesi eyer ya da çadır olsun 2 mm' den azsa tip 3 olarak adlandırılmaktadır (Resim 3).

Tanımlanan EKG örneklerinden tip 1 tanı koydurucu iken tip 2 ve 3 tanı koydurucu değildir. Brugada sendromu bazen çok hafif EKG değişiklikleri ile birlikte gizli olarak bulunmaktadır (8). Bunun yanında Brugada Sendromunda klinik ve EKG bulgularının ortaya çıkışını kolaylaştıran bazı durumlar vardır. Sodyum kanal blokerleri, beta ve alfa blokerler gibi hipertansiyon ve ritim bozukluklarında önerilen ilaçlar, ateşli durumlar, antidepresanlar, glukoz ve insülin kombinasyonu, alkol ve kokain toksisitesi ST segment elevasyonunu arttırırlar $(9,10)$

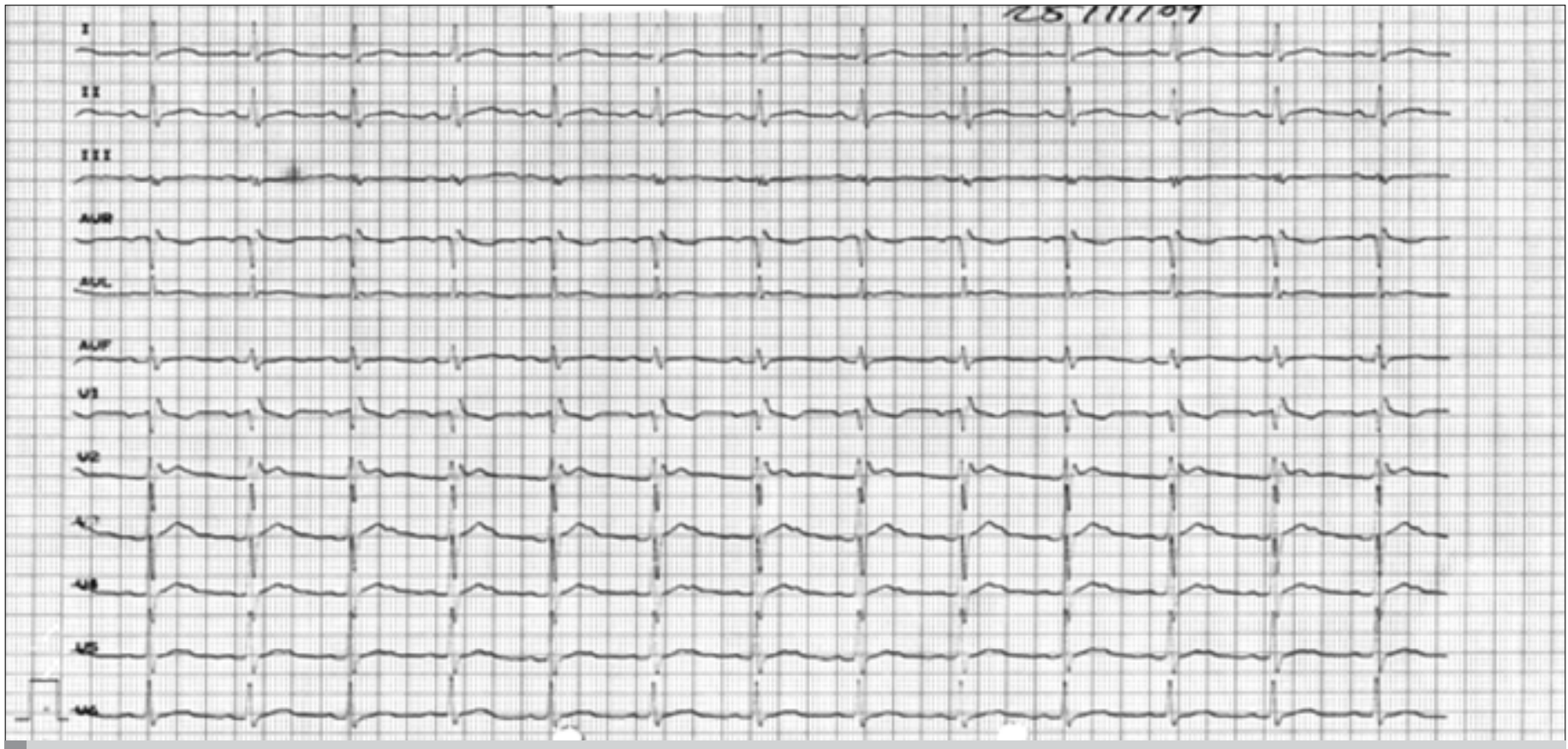

Resim 1. Hastanın istirahat EKG'si 


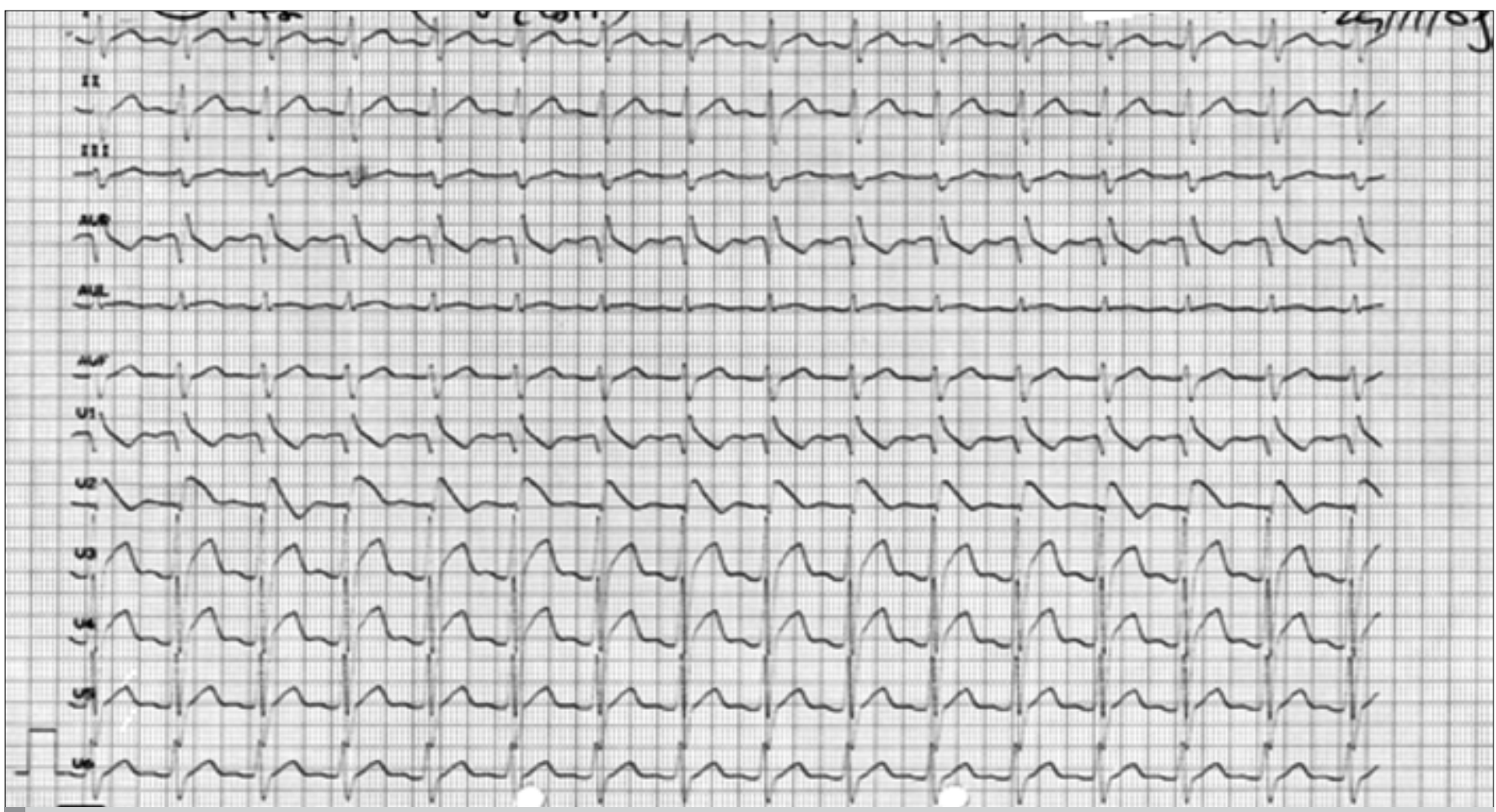

Resim 2. Ajmalin testi ile elde edilen EKG

Brugada sendromundan şüphelenilen hastalarda tanı amaçlı olarak flekainid, ajmalin, prokainamid, dizopiramid, propafenon, ve pilsikainid gibi sodyum kanal blokerleri, risk altındaki hastaları ortaya çıkarmaktaki özgünlüğü tam olarak bilinmemekle birlikte kullanılmaktadır. Bu ajanlar sağ ventrikül epikardiyumunda aksiyon potansiyelini arttırarak Brugada Sendromunda gizli kalmış EKG bulgularının açığa çıkarılmasına yardımcı olarak kullanılır. Bu ilaçların kontreendike olmadığı durumlarda, tip 2 ve 3 EKG örneği olan olgularda tip 1 Brugada EKG örneğini ortaya çıkarma girişimi zaman zaman kullanılagelen bir test aracı olmuştur. Hastamızda olduğu gibi ailede ani ölüm öyküsü olan ve EKG'sinde Brugada sendromu için tipik olmayan Tip 2 ve Tip 3 EKG bulguları olan bir hastada, Na kanal blokeri ile test tanıda çok değerlidir. Bu ilaçlar için önerilen dozlar Tablo 1'de özetlenmiştir. Bu ilaçların farmakokinetik etki mekanizmaları dolayısıyla tanı koydurucu değerleri, duyarlık ve özgüllükleri farklıık göstermektedir. Bunlardan flekainid ve prokainamidin ajmaline göre tanısal değeri daha düşüktür. Bu nedenle tüm dünyada en sık bu amaçla ajmalin kullanılmaktadır (11).

Ajmalin belirli dozda intravenöz yolla uygulanır ve Brugada tip 1 EKG örneği oluşması için hasta monitörize edilir. En sık benimsenen uygulama yöntemi $1 \mathrm{mg} / \mathrm{kg}$ dozunda 5 dk infüzyon şeklinde (11) ve toplam 1 mg/kg dozunu geçmeyecek şekilde her iki dakikada bir 10 mg uygulanmasıdır $(12,13)$. Akılda tutulması gereken, bu ilaçların olası proaritmik etkileri nedeniyle test yapılırken tüm önlemlerin alınması gerektiğidir. Test sırasında devamlı EKG kaydı yapılmalıdır. Geniş ORS, geniş P dalgası veya uzun PR olan hastalarda tam AV blok gelişebileceğinden yakından takip edilmelidir $(12,13)$. Test esnasında nadiren de olsa hastalarda nabızsız elektriksel aktivite gelişebileceği unutulmamaIı, izopretrenol ve sodyum laktat hazır bulundurulmalıdır.

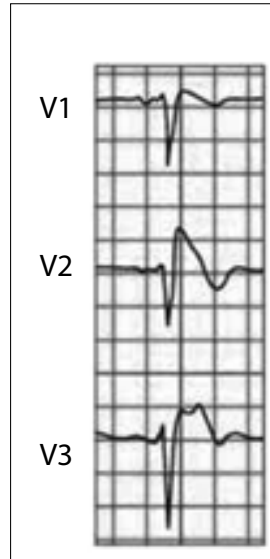

Tip 1

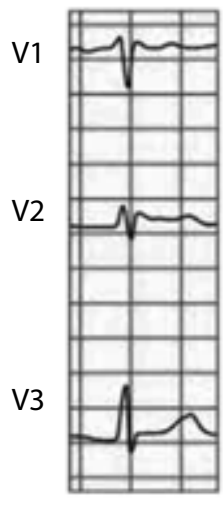

Tip 2
V1

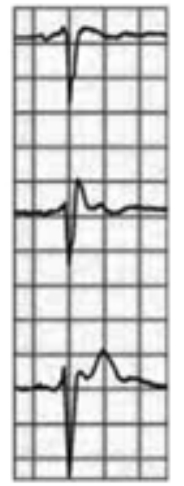

Tip 3
Resim 3. Brugada Sendromu Sınıflaması (Braunwald EKG arşivinden)

Tablo 1. Brugada sendromunu açığa çıkarmak için kullanılan ilaçlar

\begin{tabular}{ll} 
İlaçlar & Dozlar \\
\hline Ajmalin & $1 \mathrm{mg} / \mathrm{kg}$ ile 5 dk iv infüzyon \\
\hline Flekainamide & $2 \mathrm{mg} / \mathrm{kg}$ ile 10dk iv infüzyon ya da $400 \mathrm{mg}$ oral \\
\hline Prokainid & $10 \mathrm{mg} / \mathrm{kg}$ ile 10dk iv infüzyon \\
\hline Pilsikainide & $1 \mathrm{mg} / \mathrm{kg}$ ile 10dk iv infüzyon \\
\hline
\end{tabular}


Test sırasında Brugada sendromu için tanısal tip 1 EKG değişikliği oluşursa, Tip 2 EKG de ST segmenti $\geq 2 \mathrm{~mm}$ olursa, ventriküler erken vurular veya diğer aritmiler gelişirse, QRS bazal değerinin $\geq \% 130$ 'dan daha fazla uzarsa test sonlandırımalıdır. Test sırasında Brugada Sendromu için tanısal olan tip 1 EKG oluşursa test pozitif kabul edilmelidir (11).

\section{Sonuç}

Brugada Sendromunun tanısı güçtür ve bu durum yüksek hayati risk taşımaktadır. Acil servise EKG'de V1-V3 derivasyonlarında ST yükselmesi, senkop, VT veya ani ölümle başvuran hastalarda ayırıcı tanıda Brugada Sendromu dikkate alınmalıdır. Bunun yanında şüpheli EKG bulguları varlığında elektrofizyolojik çalışmanın yanı sıra provakasyon testleri yardımcıdır.

Conflict of Interest: No conflict of interest was declared by the authors.

Peer-review: Externally peer-reviewed.

Informed Consent: Written informed consent was obtained from patients who participated in this case.

Author Contributions: Concept - S.D.; Design - S.D.; Supervision M.K., S.D.; Funding - M.T.; Materials - M.K., S.D.; Data Collection and/ or Processing - Z.K., V.A.; Analysis and/or Interpretation - M.T., S.D.; Literature Review - Z.K., V.A.; Writer - S.D.; Critical Review - S.D., V.A.

Financial Disclosure: The authors declared that this study has received no financial support.

Çıkar Çatışması: Yazarlar çıkar çatışması bildirmemişlerdir.

Hakem değerlendirmesi: Dış bağımsız.

Hasta Onamı: Yazılı hasta onamı bu olguya katılan hastalardan alınmıştır.

Yazar Katkıları: Fikir - S.D.; Tasarım - S.D.; Denetleme - M.K., S.D.; Kaynaklar - M.T.; Malzemeler - M.K., S.D.; Veri toplanması ve/veya işlemesi - Z.K., V.A.; Analiz ve/veya yorum - S.D., M.T.; Literatür taraması - Z.K., V.A.; Yazıyı yazan - S.D.; Eleştirel İnceleme - S.D., V.A.
Finansal Destek: Yazarlar bu çalışma için finansal destek almadıklarını beyan etmişlerdir.

\section{Kaynaklar}

1. Brugada P, Brugada J. Right bundle branch block, persistent ST segment elevation and sudden cardiac death: a distinct clinical and electrocardiographic syndrome. A multicenter report. J Am Coll Cardiol 1992; 20: 1391-6.

2. Antzelevitch C, Brugada P, Brugada J, Brugada R, Towbin JA, Nademanee K. Brugada syndrome: 1992-2002: A historical perspective. J Am Coll Cardiol 2003; 41: 1665-71.

3. Akdemir İ, Davutoğlu V, Dinckal MH, Aksoy M. Akut myokard infarktüsü tanısı ile karıştırılan bir brugada sendromu olgusu. Turk Kardiyol Dern Arş 2001; 29: 723-6.

4. Brugada J, Brugada R, Brugada P. Right bundle-branch block and STsegment elevation in leads V1 through V3: A marker for sudden death in patients without demonstrable structural heart disease. Circulation 1998; 97: 457-60.

5. Wilde AA, Antzelevitch C, Borggrefe M, Brugada J, Brugada R, Brugada P, et al. Proposed diagnostic criteria for the Brugada syndrome. Eur Heart J 2002; 23: 1648-54

6. Wilde AA, Antzelevitch C, Borggrefe M, Brugada J, Brugada R, Brugada P, et al. Proposed diagnostic criteria for the Brugada syndrome: Consensus report. Circulation 2002; 106: 2514-9.

7. Morita H, Kusano-Fukushima K, Nagase S, Fujimoto Y, Hisamatsu K, Fujio $\mathrm{H}$, et al. Atrial fibrillation and atrial vulnerability in patients with Brugada syndrome. J Am Coll Cardiol 2002; 40: 1437-44.

8. Gussak I, Bjerregaard P, Hammill SC. Clinical diagnosis and risk stratification in patients with Brugada syndrome. J Am Coll Cardiol 2001; 37: 1635-8.

9. Tatli E, Gul C, Surucu H, Ozcelik F. Brugada syndrome: Clinical evaluation, diagnosis and treatment modalities: Reiew. Turkiye Klinikleri J Med Sci 2005; 25: 560-4.

10. Brugada J, Brugada R, Brugada P. Right bundle-branch block and STsegment elevation in leads V1 through V3: a marker for sudden death in patients without demonstrable structural heart disease. Circulation 1998; 97: 457-60.

11. Brugada R, Brugada J, Antzelevitch C, Kirsch GE, Potenza D, Towbin JA et al. Sodium channel blokers identfy risk for sudden death in patients with ST segment elevation and right bundle branch block but structurally normal hearts. Circulation 2000; 101: 510-5.

12. Demirtaş S, Atar I, Köse S. Ajmalin testi. Türk Aritmi Pacemaker ve Elektrofizyoloji Dergisi 2008; 6: 1.

13. Rolf S, Bruns HJ, Wichter T, Kirchhof P, Ribbing M, Wasmer K, et al. The ajmaline challenge in Brugada syndrome: Diagnostic impact, safety, and recommended protocol. Eur Heart J 2003; 24: 1104-12. 